\title{
Matéria orgânica e agregação do solo após conversão de "campos de murundus" em sistema plantio direto
}

\author{
Edicarlos Damacena de Souza(1), Marco Aurélio Carbone Carneiro(2), \\ Helder Barbosa Paulino ${ }^{(3)}$, Diego Oliveira Ribeiro( ${ }^{(4)}$, Cimélio Bayer ${ }^{(5)}$ e Leonardo André Rotta ${ }^{(3)}$
}

\begin{abstract}
(1)Universidade Federal de Mato Grosso, Campus Universitário de Rondonópolis, Rodovia MT-270, Km 06, CEP 78735-910 Rondonópolis, MT, Brasil. E-mail: edicarlos@pq.cnpq.br (2)Universidade Federal de Lavras, Departamento de Ciência do Solo, Caixa Postal 3037, CEP 37200-000 Lavras, MG, Brasil. E-mail: marcocarbone@dcs.ufla.br (3)Universidade Federal de Goiás, Departamento de Agricultura, Regional Jataí, BR 364, Km 192, Zona Rural, CEP 75800-000 Jataí, GO, Brasil. E-mail: helderlino51@yahoo.com.br leonardorotta@gmail.com ${ }^{(4)}$ Centro Universitário de Mineiros, Departamento de Agronomia, Rua 22, Setor Aeroporto, CEP 75830-000 Mineiros, GO, Brasil. E-mail: diegoribe@yahoo.com.br (5)Universidade Federal do Rio Grande do Sul, Departamento de Solos, Avenida Bento Gonçalves, no 7712, CEP 91540-000 Porto Alegre, RS, Brasil. E-mail: cimelio.bayer@ufrgs.br
\end{abstract}

Resumo - $\mathrm{O}$ objetivo deste trabalho foi avaliar o efeito da conversão de áreas de campos de murundus para sistemas agrícolas de plantio direto (PD) nos estoques de $\mathrm{C}$ orgânico e de $\mathrm{N}$ total do solo, em suas frações na matéria orgânica do solo e na estabilidade de agregados. O estudo foi realizado em uma cronossequência com 7, 11 e 16 anos de conversão para o PD, e em duas áreas de referência caracterizadas como topo dos murundus (TM) e entre os murundus (EM). $\mathrm{O}$ teor de $\mathrm{C}$ nos solos variou de acordo com o tempo de conversão para áreas agrícolas, em todas as profundidades, com exceção da área EM. Os estoques de $\mathrm{C}$ sofreram efeitos negativos da conversão da área nativa em agrícola, e os maiores estoques foram observados nas áreas EM e TM. O índice de manejo de $\mathrm{C}$ aumentou com o tempo de adoção do PD, em relação ao TM, e os atributos do solo melhoraram com o aumento no tempo de adoção de 7 para 16 anos de $\mathrm{PD}$, mas os estoques de C orgânico nas áreas convertidas não retornam aos níveis observados nas áreas referências.

Termos para indexação: Cerrado, cronossequência de cultivos, estabilidade de agregados, estoque de carbono no solo, fração lábil, índice de manejo do carbono.

\section{Organic matter and soil aggregation after the conversion of "murundu fields" into a no-tillage system}

\begin{abstract}
The objective of this work was to evaluate the effect of the conversion of "murundu" (little natural mounds) field areas into no-tillage agricultural systems on the stocks of soil organic $\mathrm{C}$ and total $\mathrm{N}$, on their fractions in soil organic matter, and on aggregate stability. The study was carried out in a chronosequence of 7 , 11 , and 16 years of conversion into a no-tillage system, and in two reference areas characterized as top mounds (TM) and between mounds (BM). Soil C content varied according to the time of conversion into agricultural areas at all soil depths, except in the BM area. Organic $\mathrm{C}$ stocks showed negative effects of the conversion of native area into an agricultural system, and the largest stocks were observed in the BM and TM areas. The carbon management index increased over time after no-tillage adoption, in relation to TM, and soil properties improved with the increase in PD adoption time from 7 to 16 years, but organic $\mathrm{C}$ stocks in the converted areas did not return to the levels observed in the reference areas.
\end{abstract}

Index terms: Cerrado, crop chronosequence, aggregate stability, soil carbon stock, labile fraction, carbon management index.

\section{Introdução}

O bioma Cerrado ocupa uma área de 34 milhões de hectares no Estado de Goiás, cujas principais classes de solo são os Latossolos, com 52\% da área, seguidos por Argissolos, Neossolos e Cambissolos, correspondentes a 15,13 e $12 \%$ da área, respectivamente. Além dessas classes, há a ocorrência de Plintossolos, que representam
4\% dos solos do bioma e, geralmente, estão associados à fitofisionomia denominada "campos de murundus" ou "covais". Nessa fitofisionomia, provavelmente em consequência da ação de térmitas, ocorrem elevações de solo denominadas murundus, com tamanho que pode atingir $2 \mathrm{~m}$ de altura e até $20 \mathrm{~m}$ de diâmetro (Motta et al., 2002). Nesses solos, a infiltração de água é lenta e, portanto, alagamentos entre os murundus são 
comuns durante o período chuvoso, o que torna esses campos de extrema importância para a redistribuição e manutenção dos mananciais de água da região (Resende et al., 2004).

No processo de incorporação dessas áreas a sistemas agrícolas de produção, é necessário o nivelamento do terreno, com destruição dos murundus, e construção de grandes drenos, além da correção e adubação do solo. Inicialmente, os solos são manejados sob sistema de plantio convencional e, posteriormente, sob sistema plantio direto; no entanto, não há estudos sobre os efeitos dessa conversão sobre os atributos do solo. Apesar da fragilidade dessa fitofisionomia e de sua função ecológica referente à dinâmica da água na microbacia, grande parte dessas áreas foram inseridas no processo produtivo do agronegócio anteriormente à lei estadual de Goiás que a protege (Goiás, 2007).

A conversão de ecossistemas naturais em áreas agrícolas promove alterações dos estoques de $\mathrm{C}$ e $\mathrm{N}$ do solo, como relatado em: Latossolo Vermelho, em Minas Gerais (Rangel \& Silva, 2007); Argissolo Vermelho-Amarelo de Zona da Mata (Portugal et al., 2008); Nitossolos da Região Amazônica (Carvalho et al., 2010); Latossolo, no Cerrado do Piauí (Leite et al., 2010); e em Latossolos de Cerrado (Siqueira-Neto et al., 2010). Esses atributos são utilizados no monitoramento da qualidade do solo. Entretanto, somente os estoques de $\mathrm{C}$ orgânico total e o $\mathrm{N}$ total podem, muitas vezes, não indicar as variações que ocorrem em curto período de tempo. Assim, são frequentes as avaliações de frações lábeis da matéria orgânica, com o objetivo de monitorar o impacto de sistemas de uso e manejo em curto prazo (Souza et al., 2009; Conte et al., 2011).

Em regiões tropicais, em consequência das temperaturas elevadas e altos índices pluviais, há um aumento da atividade microbiana do solo que propicia a rápida decomposição dos materiais orgânicos depositados no solo (Assis et al., 2003; Belo et al., 2012). Portanto, em ecossistemas cuja vegetação nativa foi substituída por sistemas agrícolas, com intenso revolvimento, os estoques de $\mathrm{C}$ orgânico podem diminuir logo nos primeiros anos (Leite et al., 2010).

Para reverter o processo de degradação do solo, sistemas conservacionistas de manejo do solo, como o plantio direto, são adotados e resultam em melhoria significativa da qualidade física, química e biológica do solo (Siqueira-Neto et al., 2010; Vezzani \& Mielniczuk,
2011). Essa melhoria é promovida por alguns fatores, como: proteção física dos compostos orgânicos contra a decomposição microbiana, favorecida pela oclusão do $\mathrm{C}$ em agregados do solo; e a proteção química dos compostos, por meio da interação destes com os minerais e cátions do solo, o que dificulta a oxidação microbiana (Siqueira-Neto et al., 2010). Além disso, por não haver revolvimento do solo, ocorre redução da fragmentação dos resíduos, com consequente diminuição do contato solo/resíduo, o que promove menor decomposição do resíduo pela biota do solo. No entanto, não há relato, na literatura, sobre os efeitos da conversão de campos de murundus para sistemas agrícolas, bem como da adoção do sistema plantio direto sobre os estoques de $\mathrm{C}$ e $\mathrm{N}$, as frações da matéria orgânica do solo e a relação destas com a agregação do solo, nessa fitofisionomia.

O objetivo deste trabalho foi avaliar o efeito da conversão de áreas de campos de murundus para sistemas agrícolas de plantio direto nos estoques de $\mathrm{C}$ orgânico e $\mathrm{N}$ total do solo, em suas frações na matéria orgânica do solo e na estabilidade dos agregados.

\section{Material e Métodos}

O estudo foi realizado na Fazenda Boa Vista, a cerca de $60 \mathrm{~km}$ do Município de Jataí, na Microbacia do Rio Ariranha, no sudoeste do Estado de Goiás (1757'59"S e $\left.52^{\circ} 04^{\prime} 35^{\prime \prime} \mathrm{W}\right)$. O solo da área foi classificado como Plintossolo Háplico de textura argilosa (450, 50 e 500 $\mathrm{g} \mathrm{kg}^{-1}$ de argila, silte e areia, respectivamente). O clima da região, segundo a classificação de Köppen-Geiger, é do tipo $\mathrm{CW}$ - mesotérmico, com estações seca e chuvosa bem definidas. A temperatura média anual do local dos tratamentos é de $22^{\circ} \mathrm{C}$, e a precipitação pluvial anual varia de 1.600 a $1.800 \mathrm{~mm}$, com duas estações bem definidas - uma quente e chuvosa, de outubro a abril, e outra com clima mais ameno e seco, de maio a setembro.

Os tratamentos constituíram-se do tempo de conversão do campo de murundus para sistemas agrícolas, em plantio direto, por 7 (PD7), 11 (PD11) e 16 anos (PD16), cujas características químicas encontramse na Tabela 1. Além das áreas cultivadas, utilizou-se como referência a área de campo de murundus sem interferência antrópica, tendo-se considerado duas situações distintas: o topo dos murundus (TM) e entre os murundus (EM). Esta diferenciação foi feita em 
razão da composição da vegetação e do alagamento que ocorre entre os murundus.

Para a conversão das áreas nativas para a de atividade agrícola, inicialmente, no período seco, fez-se a queimada da vegetação presente e, posteriormente, o preparo do solo com arado. Para o nivelamento da área, os murundus foram inicialmente destruídos com lâminas frontais e de arrasto, e a terra foi removida para o espaço entre os locais onde os murundus estavam. Em seguida realizou-se a subsolagem de toda a área e o aplainamento do terreno com grade niveladora. Para o escoamento da água, foram construídos drenos com espaçamento de $100 \mathrm{~m}$ entre si (Tabela 2).

Tabela 1. Atributos químicos das áreas agrícolas e dos campos de murundus no Cerrado, na camada de $0,0-20 \mathrm{~cm}$.

\begin{tabular}{lcccccccc}
\hline Área & $\begin{array}{c}\mathrm{pH} \\
\mathrm{H}_{2} \mathrm{O}\end{array}$ & $\begin{array}{c}\mathrm{Ca} \\
-----\end{array}$ & $\begin{array}{c}\mathrm{Mg} \\
\left(\mathrm{cmol}_{\mathrm{c}} \mathrm{dm}^{-3}\right)\end{array}$ & $\begin{array}{c}\mathrm{Al} \\
\text {---- }\end{array}$ & $\begin{array}{c}\mathrm{K} \\
-\left(\mathrm{mg} \mathrm{dm}^{-3}\right)\end{array}$ & $\begin{array}{c}\mathrm{P} \\
\mathrm{T}\left(\mathrm{cmol}_{\mathrm{c}}\right. \\
\left.\mathrm{dm}^{-3}\right)\end{array}$ & $\begin{array}{c}\mathrm{V} \\
(\%)\end{array}$ \\
\hline TM & 4,9 & 0,04 & 0,24 & 0,72 & 23,8 & 0,40 & 7,69 & 4,4 \\
EM & 5,5 & 0,05 & 0,22 & 0,22 & 18,1 & 0,30 & 5,44 & 5,8 \\
PD7 & 5,7 & 1,75 & 0,71 & 0,09 & 27,7 & 2,24 & 7,00 & 36,1 \\
PD11 & 5,8 & 2,65 & 0,96 & 0,09 & 30,9 & 2,33 & 6,65 & 51,4 \\
PD16 & 6,1 & 2,68 & 1,11 & 0,06 & 76,3 & 2,31 & 7,99 & 48,4 \\
\hline
\end{tabular}

TM, topo dos murundus; EM, área entre os murundus; PD7, plantio direto por sete anos; PD11, plantio direto por 11 anos; e PD16, plantio direto por 16 anos.
Em cada área estudada, demarcaram-se vários polígonos de 100x100 m, que formou uma grade e, posteriormente selecionaram-se cinco polígonos de forma aleatória. Dentro de cada polígono (georreferenciado), coletaram-se cinco subamostras representativas da área, para formar uma amostra composta. As áreas estão localizadas uma ao lado da outra, em condições similares de solo, topografia, clima e manejo, e diferem apenas quanto ao período de tempo de implantação desses sistemas. Assim, os dados foram analisados como um delineamento inteiramente casualizado, com cinco repetições.

Para as coletas de solo, realizadas em setembro de

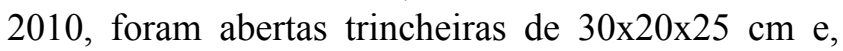
com auxílio de uma espátula, as amostras de solo foram retiradas das camadas de $0,0-2,5,2,5-5,0,5,0-7,5$, $7,5-10,0,10,0-15,0$ e $15,0-20,0 \mathrm{~cm}$ e acondicionadas em sacos de plástico, a fim de se avaliar o $\mathrm{C}$, o N e suas frações. Para a avaliação da agregação do solo, as amostras foram coletadas de blocos de solo indeformado retirados da camada de $0,0-20,0 \mathrm{~cm}$, com posterior envolvimento em filme de PVC, para manter a estabilidade da estrutura, e foram acondicionadas em sacos de plástico. As amostras deformadas foram secas ao ar e passadas em peneira de $2 \mathrm{~mm}$, enquanto as indeformadas foram retiradas do filme de PVC,

Tabela 2. Descrição e histórico das áreas estudadas.

\begin{tabular}{|c|c|}
\hline Identificação & Histórico \\
\hline $\begin{array}{l}\text { Topo dos murundus (TM) e } \\
\text { entre os Murundus (EM) }\end{array}$ & $\begin{array}{l}\text { Área sem intervenção antrópica. Os murundus apresentam diâmetro médio de } 6 \mathrm{~m} \text { e altura em torno de } 1 \mathrm{a} 2 \mathrm{~m} \text {. A parte } \\
\text { superior dos murundus (TM) apresenta vegetação típica de Cerrado stricto sensu, com elevada diversidade de plantas } \\
\text { arbustivas, arbóreas e rasteiras e constante presença de cupins. A coleta de solo foi realizada no terço superior do murundu. } \\
\text { Entre os murundus (EM) ocorreu uma lâmina de água em torno de } 10 \mathrm{~cm} \text { de altura no período chuvoso e presença de } \\
\text { espécies vegetais tolerantes ao alagamento, com predominância do gênero Syngonanthus sp. A área tem em torno de } \\
148 \text { ha, com } 33 \text { murundus. }\end{array}$ \\
\hline Área com 16 anos & $\begin{array}{l}\text { Área que sofreu intervenção antrópica desde } 1994 \text {. Nesse ano, aplicaram-se } 3,0 \mathrm{Mg} \mathrm{ha}^{-1} \text { de calcário dolomítico, tendo-se } \\
\text { utilizado arado e grade niveladora para a incorporação. Ao plantio inicial, aplicou-se } 1,0 \mathrm{Mg} \text { ha }{ }^{-1} \text { de fosfato reativo ( } 33 \% \\
\mathrm{P}_{2} \mathrm{O}_{5} \text { ) e } 2 \mathrm{Mg} \text { ha }^{-1} \text { de gesso. A partir de } 1998 \text {, não houve revolvimento do solo, ou seja, utilizou-se sistema plantio direto. } \\
\text { Em } 2005 \text {, aplicou-se } 1,5 \mathrm{Mg} \mathrm{ha}^{-1} \text { de calcário dolomítico superficialmente. Nessa área, realizou-se a sucessão de cultura de } \\
\text { soja, na safra, e milho, na safrinha, tendo-se obtido a produtividade média de } 3,4 \text { e } 6,0 \mathrm{Mg} \mathrm{ha}^{-1} \text {, respectivamente. }\end{array}$ \\
\hline Área com 11 anos & $\begin{array}{l}\text { Área que sofreu intervenção antrópica desde } 1999 \text {. Inicialmente, aplicaram-se } 6,0 \mathrm{Mg} \mathrm{ha}^{-1} \text { de calcário dolomítico, } \\
\text { incorporados por meio de arado e grade niveladora. Ao plantio inicial, aplicou-se } 0,6 \mathrm{Mg} \text { ha }{ }^{-1} \text { de fosfato reativo }(33 \% \\
\left.\mathrm{P}_{2} \mathrm{O}_{5}\right) \text {. A partir de } 2000 \text {, não houve revolvimento do solo, ou seja, utilizou-se o sistema plantio direto. Nessa área, realizou- } \\
\text { se a sucessão de cultura com soja, na safra, e milho, na safrinha, até } 2005 \text {, tendo-se obtido a produtividade média de } \\
3,4 \text { e } 6,0 \mathrm{Mg} \mathrm{ha}^{-1} \text {, respectivamente e, a partir de } 2006 \text {, a sucessão foi soja/pousio. Nos anos } 2002 \text { e } 2007 \text {, aplicaram-se } \\
2,5 \mathrm{Mg} \mathrm{ha}^{-1} \text { de calcário dolomítico superficialmente. }\end{array}$ \\
\hline Área com 7 anos & $\begin{array}{l}\text { Área que sofreu intervenção antrópica desde } 2003 \text {. Inicialmente, aplicaram-se } 5,0 \mathrm{Mg} \mathrm{ha}^{-1} \text { de calcário dolomítico, } \\
\text { incorporados por meio de arado e grade niveladora. Ao plantio inicial, aplicou-se } 0,6 \mathrm{Mg} \mathrm{ha}^{-1} \text { de fosfato reativo ( } 33 \% \\
\mathrm{P}_{2} \mathrm{O}_{5} \text { ), além de } 2,0 \mathrm{Mg} \mathrm{ha}{ }^{-1} \text { de gesso agrícola. A partir de } 2004 \text {, não houve revolvimento do solo, ou seja, utilizou-se } \\
\text { plantio direto. Nessa área, a sucessão de cultura foi feita com soja, na safra, e milho (ou milheto e sorgo), na safrinha, } \\
\text { tendo-se obtido a produtividade média de } 3,1 \mathrm{Mg} \mathrm{ha}^{-1} \text { para a soja e de } 4,5 \mathrm{Mg} \mathrm{ha}^{-1} \text { para o milho. A partir de } 2007 \text {, foi feita a } \\
\text { rotação soja e milho, na safra, e pousio, na entressafra. Em } 2005 \mathrm{e} \mathrm{em} 2008 \text {, aplicou-se } 1,5 \mathrm{Mg} \text { ha de calcário dolomítico } \\
\text { superficialmente. }\end{array}$ \\
\hline
\end{tabular}


umedecidas e destorroadas em seus pontos de fraqueza e colocadas para secagem ao ar.

O fracionamento físico granulométrico do solo foi realizado conforme Cambardella \& Elliott (1992), e $20 \mathrm{~g}$ de solo foram pesados, colocados em frascos de $180 \mathrm{~mL}$, tipo snap-cap, que continham $80 \mathrm{~mL}$ de solução de hexametafosfato de sódio $\left(5 \mathrm{~g} \mathrm{~L}^{-1}\right)$. As amostras foram agitadas durante 16 horas, em agitador horizontal, a 160 batidas $\min ^{-1}$ e, posteriormente, a suspensão foi passada em peneira de $53 \mu \mathrm{m}$, com auxílio de jatos de água. O material retido na peneira foi seco em estufa a $50^{\circ} \mathrm{C}$, até atingir massa constante, e moído em gral de porcelana. Os teores de carbono orgânico total (COT) e carbono orgânico particulado (COP) foram analisados em analisador Shimadzu TOC-V CSH. Os teores de nitrogênio total (NT) e $\mathrm{N}$ da matéria orgânica particulada (N-MOP) foram determinados pelo método Kjeldahl (Tedesco et al., 1995).

Os estoques de COT, NT, COP e N-MOP foram calculados pelo método da massa equivalente de solo. $\mathrm{O}$ cálculo dos estoques de $\mathrm{C} \mathrm{e} \mathrm{N}$ tomou como referência a área com menor massa de solo, que correspondeu à área nativa do topo dos murundus. Assim, o cálculo dos estoques foi baseado nas densidades de solo $0,85,0,98$ e $0,95 \mathrm{~kg} \mathrm{dm}^{-3}$, para as camadas de $0-5,5-10$ e 10-20 $\mathrm{cm}$, respectivamente. Para o cálculo do estoque total de $\mathrm{C}$ e $\mathrm{N}$ e das frações, na camada de $0-20 \mathrm{~cm}$, realizou-se a soma dos estoques em cada camada amostrada.

O cálculo do índice de manejo de carbono (IMC) e de seus componentes foi realizado conforme Blair et al. (1995), com as adaptações de Diekow et al. (2005), em que o COP corresponde à fração lábil da MOS e o COM corresponde à fração não lábil, segundo a expressão IMC $=$ IEC $\times$ ILC $\times 100$, em que: IEC, é o estoque de COT do tratamento/estoque de COT da referência; ILC é a labilidade do $\mathrm{C}$ no tratamento/ labilidade do $\mathrm{C}$ na referência; labilidade, é o estoque de $\mathrm{C}$ orgânico lábil/estoque de $\mathrm{C}$ orgânico não lábil.

Para a determinação do tamanho dos agregados, utilizou-se o método descrito por Kemper \& Chepil (1965), modificado por Silva \& Mielniczuk (1997), que consiste na separação dos agregados em classes de tamanho. A partir desses valores, obtevese o diâmetro médio ponderado, calculado pela equação $\mathrm{DMP}=[\Sigma(\mathrm{AGRi} \times \mathrm{di} / \Sigma \mathrm{AGR}]$, em que: $\mathrm{di}$, é o diâmetro médio da classe $i$, obtido por [(malha superior + malha inferior)/2]; AGRi $=[\mathrm{mAGRi} / \mathrm{AGR}]$;
AGRi $=$ percentagem de agregados da classe $\mathrm{i} /$ massa total de agregados.

Os resultados foram submetidos à análise de variância, o teste de Tukey e a correlação de Pearson foram aplicados a $5 \%$ de probabilidade, tendo-se considerado o efeito do tempo de conversão isoladamente, em cada profundidade.

\section{Resultados e Discussão}

O teor de C orgânico apresentou pequena variação em razão do tempo de conversão para área agrícola, em todas as profundidades analisadas, com exceção da área entre os murundus (EM), tendo-se observado os maiores teores de $\mathrm{C}$ orgânico até a profundidade de $7,5 \mathrm{~cm}$ (Figura $1 \mathrm{~A}$ ). Na camada de $0-2,5 \mathrm{~cm}$, os teores de COP foram maiores na área EM, e os menores teores, na área de plantio direto com sete anos (PD7) e topo dos murundus (TM) (Figura $1 \mathrm{~B}$ ).

$\mathrm{O}$ teor de $\mathrm{N}$ foi superior na área $\mathrm{EM}$, na maioria das profundidades analisadas (Figura $1 \mathrm{C}$ ), exceto na camada superficial $(0-2,5 \mathrm{~cm})$ e na camada de 7,5-10 cm. Observou-se que o N-MOP apresentou comportamento diferente do COT, COP e NT (Figura 1 D). Na camada de $0-2,5 \mathrm{~cm}$, os maiores teores de N-MOP foram encontrados nas áreas PD11, PD16 e EM, que diferiram das demais áreas.

Verifica-se que, em diversas profundidades, os maiores teores de COT, COP e NT foram encontrados na área EM, e os menores, após 7 anos de conversão para agricultura (PD7). Isso ocorreu em razão da deposição de resíduos orgânicos, pelo escoamento superficial oriundo do topo dos murundus, e pela redução da taxa de decomposição dos resíduos, pois a área EM sofre inundação durante parte do período chuvoso anual, o que favorece a conservação da matéria orgânica no solo. Weber \& Couto (2008) estudaram solos alagados, cultivados e naturais, no Pantanal de Mato Grosso do Sul e no Rio Grande do Sul, e observaram comportamento semelhante ao do presente estudo quanto à menor taxa de decomposição em condições de alagamento. Considerando-se que na conversão da área de murundu para agrícola, o solo das áreas TM e EM foram homogeneizados, os teores de COT, COP, NT e N-MOP apresentaram reduções significativas, mesmo tendo-se adotado sistemas conservacionistas como o PD, o que indica perdas de até $52,48,34$ e $59 \%$ para o COT, COP, 
NT e N-MOP, respectivamente. Diversos estudos também mostram o efeito negativo da conversão de áreas nativas em agricultura, com redução dos teores de $\mathrm{C}$ do solo, principalmente em sistemas não consolidados, como os dos estudos de Carvalho et al. (2007), em Latossolo da Amazônia, Dieckow et al. (2009), em Latossolos de Cerrado e Latossolo e Argissolo em Campos Nativos do Rio Grande do Sul, e por Carvalho et al. (2010), em Nitossolos da Amazônia.

Para os teores de COT, NT, COP e N-MOP, observaram-se maiores concentrações nas camadas superficiais, que reduziram a concentração de $\mathrm{C}$ e $\mathrm{N}$ com o aumento da profundidade. Isso é ocasionado pela deposição de material orgânico (fitomassa) e pela manutenção da estrutura do solo. A deposição de resíduos culturais sobre o solo e o aumento de $\mathrm{MO}$ na superfície resultam em efeitos importantes sobre a ciclagem de nutrientes, a agregação e atividade microbiana do solo, o movimento e o armazenamento de água, e a troca de gases com a atmosfera, e isso pode favorecer a sustentabilidade do solo e, consequentemente, a maior produção das culturas (Bayer et al., 2004).

$\operatorname{COT}\left(\mathrm{g} \mathrm{kg}^{-1}\right)$
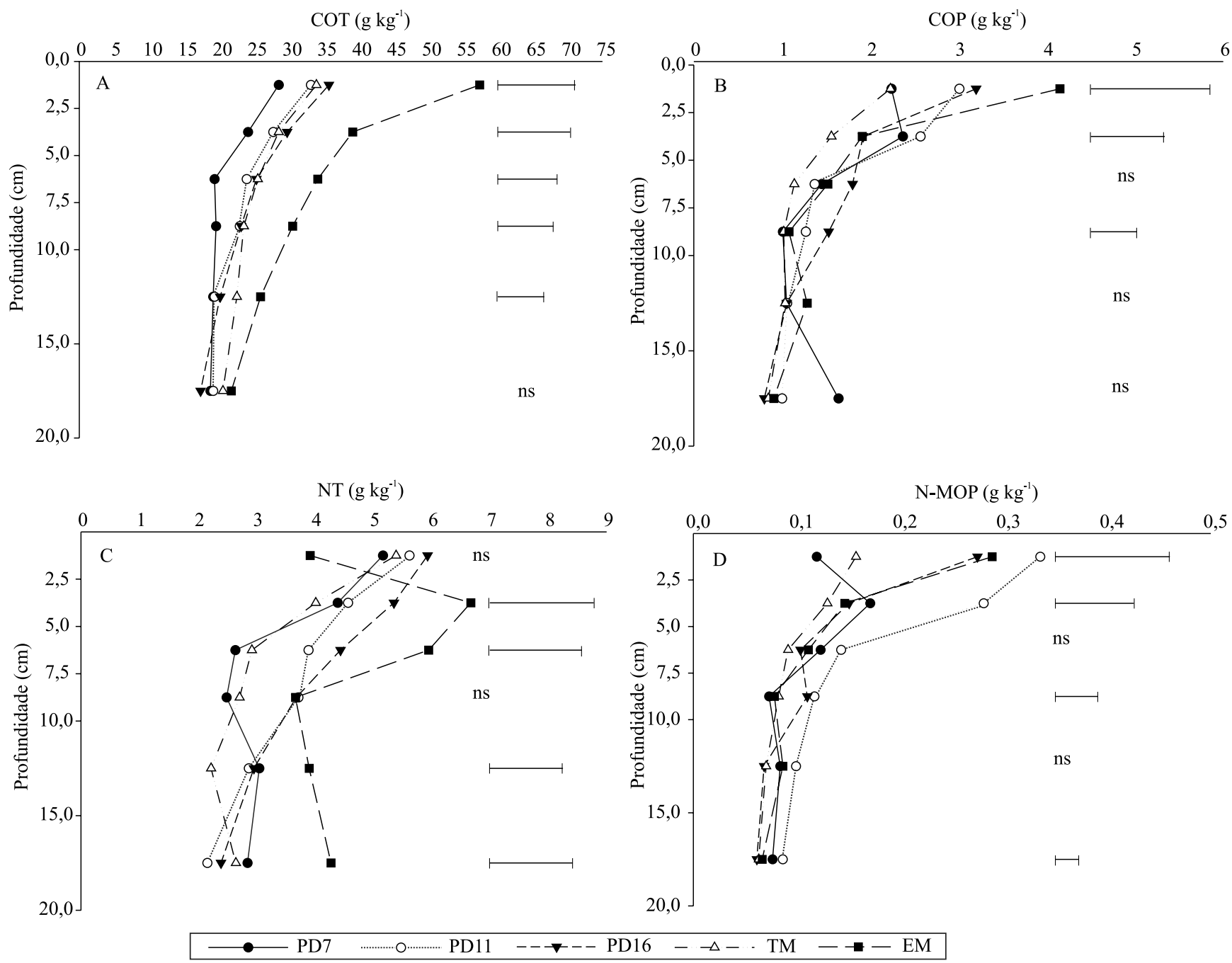

Figura 1. Teores de carbono orgânico total (A), carbono orgânico particulado (B), nitrogênio total (C) e nitrogênio na matéria orgânica particulada (D), nas áreas estudadas. PD7, plantio direto por sete anos; PD11, plantio direto por 11 anos; PD16, plantio direto por 16 anos; TM, topo dos murundus; e EM, entre os murundus. As barras referem-se a diferenças mínimas

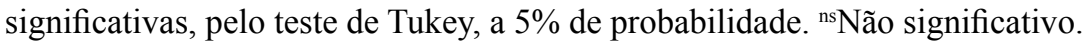


Para os estoques de COT, os resultados mostram efeitos negativos da conversão da área nativa em agrícola, e os maiores estoques foram observados na área $\operatorname{EM}\left(58,9 \mathrm{Mg} \mathrm{ha}^{-1}\right)$ e na TM (45,9 $\left.\mathrm{Mg} \mathrm{ha}^{-1}\right)$, que diferiram das demais áreas estudadas (Tabela 3 ). Apesar de a conversão da área nativa para o sistema de produção agrícola provocar reduções dos estoques de carbono, nota-se que ocorre aumento destes com o tempo de adoção de sistemas conservacionistas. Siqueira-Neto et al. (2010) afirmam que a adoção do $\mathrm{PD}$, pelo período de 12 anos, mostrou-se eficiente na recuperação dos estoques de $\mathrm{C}$ do solo, que foram semelhantes aos estoques da área de cerrado, em diferentes Latossolos no Estado de Goiás.

Ao se considerar a média dos estoques de $\mathrm{C}$ das áreas nativas (referências), obtém-se o valor de 52,4 $\mathrm{Mg} \mathrm{ha}^{-1}$ na camada $0-20 \mathrm{~cm}$. Com este valor, podese simular o tempo necessário para a recuperação dos estoques de $\mathrm{C}$, em relação à área de referência, com base na equação descrita por Mielniczuk et al. (2003). Assim, com o manejo adotado nas três áreas estudadas (PD7, PD11 e PD16), ou seja a mesma entrada e saída de $\mathrm{C}$, as áreas agrícolas apresentarão o mesmo estoque de $\mathrm{C}$ da área nativa após 34 anos. Portanto, devem-se adotar sistemas de manejo com maior aporte de $\mathrm{C}$ no solo em relação ao atual, para que se alcancem os teores referentes às áreas TM e EM em menor tempo.

Os estoques de COP apresentaram comportamento diferente dos estoques de COT (Tabela 3), e os maiores valores foram os da área EM e PD16, que foram superiores ao TM em $0,6 \mathrm{Mg} \mathrm{ha}^{-1}$ (27\%). Há uma tendência de elevação nessa fração, com o aumento de tempo de adoção do PD (até 11 anos), em comparação ao TM. A fração particulada do COT é

Tabela 3. Estoque de carbono orgânico total (COT), carbono orgânico particulado (COP), estoque de nitrogênio total (NT) e nitrogênio na matéria orgânica particulada (N-MOP), na camada de $0-20 \mathrm{~cm}^{(1)}$.

\begin{tabular}{|c|c|c|c|c|}
\hline \multirow[t]{2}{*}{ Área } & COT & COP & NT & N-MOP \\
\hline & \multicolumn{4}{|c|}{ 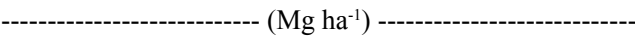 } \\
\hline TM & $45,9 \mathrm{~b}$ & $2,2 b$ & $5,8 \mathrm{~b}$ & $0,169 \mathrm{~b}$ \\
\hline EM & $58,9 \mathrm{a}$ & $2,8 \mathrm{a}$ & $8,2 \mathrm{a}$ & $0,206 \mathrm{~b}$ \\
\hline PD7 & $38,8 \mathrm{c}$ & $2,5 \mathrm{ab}$ & $6,1 \mathrm{~b}$ & $0,185 b$ \\
\hline PD11 & $43,2 b$ & $2,7 \mathrm{ab}$ & $6,2 b$ & $0,276 \mathrm{a}$ \\
\hline PD16 & $43,8 \mathrm{~b}$ & $2,8 \mathrm{a}$ & $6,9 \mathrm{ab}$ & $0,199 \mathrm{~b}$ \\
\hline
\end{tabular}

(1)Médias seguidas de letras iguais não diferem pelo teste de Tukey, a 5\% de probabilidade. PD7, plantio direto por sete anos; PD11, plantio direto, por 11 anos; PD16, plantio direto por 16 anos; TM, topo dos murundus; e EM, entre os murundus. considerada como a porção mais sensível ao manejo e está relacionada à entrada no solo de compostos mais facilmente decomponíveis, encontrados nos resíduos das culturas (Portugal et al., 2008; Souza et al., 2009; Conte et al., 2011; Vezzani \& Mielniczuk, 2011). Essa fração, no presente estudo, mostrou-se influenciada pelo sistema de manejo adotado nas áreas agrícolas (Tabela 3), tendo apresentado maior sensibilidade em comparação aos estoques de COT, como também verificado por Bayer et al. (2004) em região de clima tropical.

O estoque de NT apresentou variação entre as áreas, e os maiores valores foram observados nas áreas EM e PD16 (Tabela 3). Observa-se uma tendência de aumento com o tempo de conversão das áreas nativas para agrícolas, com incremento para o $\operatorname{PD} 7(5,2)$, PD11(6,9\%) e PD16 (19\%), em comparação ao TM. No entanto, para os estoques de N-MOP, somente PD11 foi superior e diferiu das demais áreas.

De acordo com Rangel \& Silva (2007), em ambientes naturais, o teor de $\mathrm{C}$ é determinado pela temperatura, umidade e tipo de solo. No presente estudo, em uma mesma área nativa, as condições de umidade e a vegetação apresentaram resultados diferentes, como por exemplo entre os murundus que, em razão da inundação no período chuvoso e consequente redução da atividade microbiana do solo, ocorreu o acúmulo de matéria orgânica que proporcionou maiores estoques de NT, o que corrobora os resultados encontrados por Souza et al. (2009), em estudos no Sul do Brasil.

O estoque de NT apresentou recuperação com 16 anos de experimento na área com $\mathrm{PD}$, em comparação às áreas EM e TM, em consequência do aporte deixado pelas culturas e pela aplicação constante de $\mathrm{N}$ inorgânico ao milho. Houve tendência de aumento dos estoques de NT, com o tempo de adoção do PD, o que pode ter sido ocasionado pela adição dos resíduos da soja, na safra, e do milho, no período da safrinha, além da adição de $\mathrm{N}$ à cultura do milho, por meio de fertilizantes minerais.

A labilidade do $\mathrm{C}$ foi menor na área $\operatorname{TM}(0,049)$, utilizada como referência, do que nas demais áreas (PD7, PD11 e PD16) (Tabela 4). O IMC aumentou sistematicamente com o tempo de adoção do $\mathrm{PD}$, em relação ao TM, em que as áreas agrícolas apresentaram valores superiores em 12, 28 e $39 \%$ no PD7, PD11 e PD16, respectivamente.

Pesq. agropec. bras., Brasília, v.51, n.9, p.1194-1202, set. 2016 DOI: 10.1590/S0100-204X2016000900019 
O aumento de $\mathrm{C}$ na fração lábil da MOS é importante para a elevação da qualidade do solo, pois essa é a fração mais dinâmica da matéria orgânica do solo (Diekow et al., 2005; Conte et al., 2011). Ela é fonte de energia para o sistema solo-planta, e seu aumento promove melhorias dos atributos físicos, químicos e biológicos do solo, favorece as interações do sistema solo e contribuindo, assim, para a sustentabilidade do solo (Diekow et al., 2005; Vieira et al., 2007).

O diâmetro médio ponderado (DMP) foi maior na área $\mathrm{EM}$, que diferiu das demais áreas estudadas (Figura 2). Após 16 anos de condução do PD, o DMP foi semelhante ao da área TM, o que não se observou nas áreas mais recentemente implantadas em sistemas conservacionistas (PD7 e PD11). Carneiro et al. (2015) observaram que em campos de murundus a estrutura do solo é afetada quando ocorre a conversão para a

Tabela 4. Labilidade do C (LC), índice de labilidade (ILC), índice de estoque de carbono (IEC) e índice de manejo de carbono (IMC) do solo, na camada de 0-20 cm.

\begin{tabular}{lcccl}
\hline Área & LC & ILC & IEC & IMC \\
\hline PD7 & $0,070 \mathrm{a}$ & $1,48 \mathrm{a}$ & $0,85 \mathrm{a}$ & $112 \mathrm{bc}$ \\
PD11 & $0,066 \mathrm{a}$ & $1,37 \mathrm{a}$ & $0,95 \mathrm{a}$ & $128 \mathrm{ab}$ \\
PD16 & $0,067 \mathrm{a}$ & $1,43 \mathrm{a}$ & $0,96 \mathrm{a}$ & $139 \mathrm{a}$ \\
TM & $0,049 \mathrm{~b}$ & $1,00 \mathrm{a}$ & $1,00 \mathrm{a}$ & $100 \mathrm{c}$ \\
\hline
\end{tabular}

${ }^{(1)}$ Médias seguidas de letras iguais não diferem pelo teste de Tukey, a 5\% de probabilidade. PD7, plantio direto por sete anos; PD11, plantio direto por 11 anos; PD16, plantio direto por 16 anos; e TM, topo dos murundus.

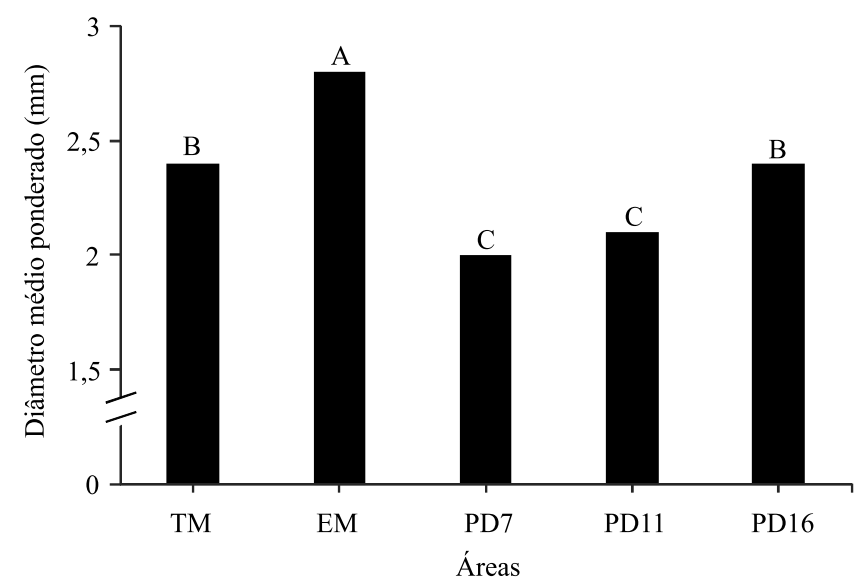

Figura 2. Diâmetro médio ponderado do solo nas áreas estudadas, na camada de 0-20 $\mathrm{cm}$. Médias seguidas de letras iguais não diferem pelo teste de Tukey, a 5\% de probabilidade. PD7, plantio direto por sete anos; PD11, plantio direto por 11 anos; PD16, plantio direto por 16 anos; $\mathrm{TM}$, topo dos murundus; e EM, entre os murundus. agricultura e que a recuperação dessa estrutura é lenta. Com isso, a diferença do DMP entre as áreas agrícolas e a EM pode ser atribuída à presença de espécies vegetais com sistema radicular agressivo que, além de promover a entrada de $\mathrm{C}$ no solo, atua no processo de agregação e melhoria da estrutura do solo. Salton et al. (2008) e Vezzani \& Mielniczuk (2011) relataram a influência das raízes sobre a formação e estabilização dos agregados, o que é corroborado pelos resultados obtidos no presente estudo. Além disso, verificou-se correlação positiva e significativa entre os estoques de $\mathrm{C}$ e o DMP $\left(\mathrm{r}=0,94^{* *}\right)$, que mostra que com o incremento dos estoques de $\mathrm{C}$, houve acréscimos ao tamanho dos agregados, com consequente aumento do DMP.

Os resultados obtidos no presente estudo mostram que está ocorrendo aumento da entrada de $\mathrm{C}$ no sistema agrícola, determinado pelo índice de manejo do $\mathrm{C}$ (Tabela 4), com o tempo de conversão da área nativa para agrícola, em razão do uso do sistema de plantio direto. No entanto, por estar próximo o novo equilíbrio dinâmico, o manejo adotado pouco contribuirá, a partir dos 16 anos, para o incremento do estoque de C, portanto, é necessária a adoção de um manejo voltado para o maior aporte de resíduos orgânicos no sistema como, por exemplo, plantas de cobertura ou mesmo a adoção do sistema de integração lavoura-pecuária. Apesar de as áreas de murundus serem protegidas por lei no Estado de Goiás (Goiás, 2007), grandes extensões de áreas foram incorporadas ao processo produtivo, anteriormente à lei, e necessitam de estudos para que se determinem manejos adequados, voltados para a reabilitação das funções ecológicas dessas áreas e associados à produção de grãos, carne, fibras e energia, pois, essa fitofisionomia é extremamente frágil e apresenta funções ecológicas importantes como o sequestro de carbono no solo.

\section{Conclusões}

1. A conversão de campos de murundus para áreas agrícolas promove redução inicial dos estoques de carbono e nitrogênio do solo, que aumentam com o tempo de adoção do sistema plantio direto; porém, sem atingir as quantidades observadas na condição original.

2. Com o atual manejo do solo e das culturas nas áreas agrícolas, estima-se que seriam necessários 34 anos para a recuperação dos estoques de matéria orgânica das condições originais. 
3. O diâmetro médio ponderado dos agregados aumenta com o tempo de adoção do sistema plantio direto e se iguala ao observado no topo dos murundus.

4. O índice de manejo de carbono indica a melhoria da qualidade solo com a adoção do plantio direto, ainda que não haja recuperação total nos estoques de carbono orgânico, em relação às áreas nos topos dos murundus e entre os murundus.

\section{Agradecimentos}

Ao Conselho Nacional de Desenvolvimento Científico e Tecnológico $\left(\mathrm{CNPq}\right.$, Processo $\mathrm{n}^{\circ}$ 559682/2009-3), pelo apoio financeiro ao Projeto e concessão de bolsas de produtividade ao primeiro, segundo e quinto autores; e à Coordenadoria de Aperfeiçoamento de Pessoal de Nível Superior (Capes), pela concessão de bolsa; ao proprietário da Fazenda Boa Vista, Jataí, GO, pela permissão de uso da área da fazenda para a condução do presente estudo.

\section{Referências}

ASSIS, E.P.M.; CORDEIRO, M.A.S.; PAULINO, H.B.; CARNEIRO, M.A.C. Efeito da aplicação de nitrogênio na atividade microbiana e na decomposição da palhada de sorgo em solo de cerrado sob plantio direto. Pesquisa Agropecuária Tropical, v.33, p.107-112, 2003.

BAYER, C.; MARTIN-NETO, L.; MIELNICZUK, J.; PAVINATO, A. Armazenamento de carbono em frações lábeis da matéria orgânica de um Latossolo Vermelho sob plantio direto. Pesquisa Agropecuária Brasileira, v.39, p.677-683, 2004. DOI: 10.1590/ S0100-204X2004000700009.

BELO, E. dos S.; TERRA, F.D.; ROTTA, L.R.; VILELA, L.A.; PAULINO, H.B.; SOUZA, E.D. de; VILELA, L.A.F.; CARNEIRO, M.A.C. Decomposição de diferentes resíduos orgânicos e efeito na atividade microbiana em um Latossolo Vermelho de Cerrado. Global Science and Technology, v.5, p.1-11, 2012.

BLAIR, G.J.; LEFROY, R.D.B.; LISLE, L. Soil carbon fractions based on their degree of oxidation, and the development of a carbon management index for agricultural systems. Australian Journal Agriculture Research, v.46, p.1459-1466, 1995. DOI: 10.1071/AR9951459.

CAMBARDELLA, C.A.; ELLIOTT, E.T. Particulate soil organicmatter changes across a grassland cultivation sequence. Soil Science Society of America Journal, v.56, p.777-783, 1992. DOI: 10.2136/sssaj 1992.03615995005600030017x.

CARNEIRO, M.A.C.; FERREIRA, D.A.; SOUZA, E.D.; PAULINO, H.B.; SAGGIN JUNIOR, O.J.; SIQUEIRA, J.O. Arbuscular mycorrhizal fungi in soil aggregates from fields of "murundus" converted to agriculture. Pesquisa Agropecuária
Brasileira, v.50, p.313-321, 2015. DOI: 10.1590/S0100204X2015000400007.

CARVALHO, J.L.N.; CERRI, C.E.P.; CERRI, C.C.; FEIGL, B.J.; PÍCCOLO, M.C.; GODINHO, V.P.; HERPIN, U. Changes of chemical properties in an Oxisol after clearing of native Cerrado vegetation for agricultural use in Vilhena, Rondonia State, Brazil. Soil and Tillage Research, v.96, p.95-102, 2007. DOI: 10.1016/j. still.2007.04.001.

CARVALHO, J.L.N.; ROUCCI, G.S.; CERRI, C.E.P.; BERNOUX, M.; FEILG, B.J.; WRUCK, F.J.; CERRI, C.C. Impact of pasture, agriculture and crop-livestock systems on soil C stocks in Brazil. Soil and Tillage Research, v.110, p.175-186, 2010. DOI: 10.1016/j.still.2010.07.011.

CONTE, O.; WESP, C. de L.; ANGHINONI, I.; CARVALHO, P.C. de F.; LEVIEN, R.; NABINGER, C. Densidade, agregação e frações de carbono de um Argissolo sob pastagem natural submetida a níveis de ofertas de forragem por longo tempo. Revista Brasileira de Ciência do Solo, v.35, p.579-587, 2011. DOI: 10.1590/S010006832011000200027.

DIECKOW, J.; BAYER, C.; CONCEIÇÃO, P.C.; ZANATTA, J.A.; MARTIN-NETO, L.; MILORI, D.B.M.; SALTON, J.C.; MACEDO, M.M.; MIELNICZUK, F.J.; HERNANI, L.C. Land use, tillage, texture and organic matter stock and composition in tropical and subtropical Brazilian soils. European Journal of Soil Science, v.60, p.240-249, 2009. DOI: 10.1111/j.13652389.2008.01101.x.

DIEKOW, J.; MIELNICZUK, J.; KNICKER, H.; BAYER, C.; DICK, D.P.; KNABNER, I.K. Carbon and nitrogen stocks in physical fractions of a subtropical Acrisol as influenced by longterm no-till cropping systems and N fertilization. Plant and Soil, v.268, p.319-328, 2005. DOI: 10.1007/s11104-004-0330-4.

GOIÁS. Lei $\mathrm{n}^{\circ} 16.153$, de 26 de outubro de 2007. Dispõe sobre a preservação dos campos de murundus, também conhecidos como covais e dá outras providências. Diário Oficial [do] Estado de Goiás, 12 nov. 2007.

KEMPER, W.D.; CHEPIL, W.S. Size distribution of aggregates. In: BLACK, C.A. (Ed.). Methods of soil analysis. Part 1. Physical and mineralogical properties, including statistics of measurement and sampling. Madison: American Society of Agronomy, 1965. p.499-510. DOI: 10.2134/agronmonogr9.1.c39.

LEITE, L.F.C.; GALVÃO, S.R.S.; HOLANDA-NETO, M.R.; ARAÚJO, F.S.; IWATA, B.F. Atributos químicos e estoques de carbono em Latossolo sob plantio direto no Cerrado do Piauí. Revista Brasileira de Engenharia Agrícola e Ambiental, v.14, p.1273-1280, 2010. DOI: 10.1590/S1415-43662010001200004.

MIELNICZUK, J.; BAYER, C.; VEZZANI, F.M.; LOVATO, T.; FERNANDES, F.F.; DEBARBA, L. Manejo de solos e culturas e sua relação com os estoques de carbono e nitrogênio do solo. In: CURI, N.; MARQUES, J.J.; GUILHERME, L.R.G.; LIMA, J.M. de; LOPES, A.S.; ALVAREZ V., V.H. Tópicos em ciência do solo. Viçosa: Sociedade Brasileira de Ciência do Solo, 2003. v. 3, p. 209248.

MOTTA, P.E.F. da; CARVALHO FILHO, A. de; KER, J.C.; PEREIRA, N.R.; CARVALHO JÚNIOR, W. de; BLANCANEAUX, P. Relações solo-superfície geomórfica e evolução da paisagem em 
uma área do Planalto Central Brasileiro. Pesquisa Agropecuária Brasileira, v.37, p.868-878, 2002. DOI: 10.1590/S0100204X2002000600017.

PORTUGAL, A.F.; JUCKSCH, I.; SCHAEFER, C.E.G.R.; WENDLING, B. Determinação de estoques totais de carbono e nitrogênio e suas frações em sistemas agrícolas implantados em Argissolo Vermelho-Amarelo. Revista Brasileira de Ciência do Solo, v.32, p.2091-2100, 2008. DOI: 10.1590/S010006832008000500030 .

RANGEL, O.J.P.; SILVA, C.A. Estoques de carbono e nitrogênio e frações orgânicas de Latossolo submetido a diferentes sistemas de uso e manejo. Revista Brasileira de Ciência do Solo, v.31, p.1609-1623, 2007. DOI: 10.1590/S0100-06832007000600037.

RESENDE, I.L. de M.; ARAÚJO, G.M. de; OLIVEIRA, A.P. de A.; ÁVILA JÚNIOR, R.S. de. A comunidade vegetal e as características abióticas de um campo de murundu em Uberlândia, MG. Acta Botanica Brasileira, v.18, p.9-17, 2004. DOI: 10.1590/ S0102-33062004000100002.

SALTON, J.C.; MIELNICZUK, J.; BAYER, C.; BOENI, M.; CONCEIÇÃO, P.C.; FABRÍCIO, A.C.; MACEDO, M.C.M.; BROCH, D.L. Agregação e estabilidade de agregados do solo em sistemas agropecuários em Mato Grosso do Sul. Revista Brasileira de Ciência do Solo, v.32, p.11-21, 2008. DOI: 10.1590/ S0100-06832008000100002.

SILVA, I.F. da; MIELNICZUK, J. Avaliação do estado de agregação do solo afetado pelo uso agrícola. Revista Brasileira de Ciência do Solo, v.21, p.313-319, 1997.

SIQUEIRA-NETO, M.; SCOPEL, E.; CORBEELS, M.; CARDOSO, A.N.; DOUZET, J.-M.; FELLER, C.; PICCOLO, M. de C.; CERRI, C.C.; BERNOUX, M. Soil carbon stocks under notillage mulch-based cropping systems in the Brazilian Cerrado: An on-farm synchronic assessment. Soil and Tillage Research, v.110, p.187-195, 2010. DOI: 10.1016/j.still.2010.07.010.

SOUZA, E.D. de; COSTA, S.E.V.G. de A.; ANGHINONI, I.; CARVALHO, P.C. de F.; ANDRIGUETI, M.; CAO, E. Estoques de carbono orgânico e de nitrogênio no solo em sistema de integração lavoura-pecuária em plantio direto, submetido a intensidades de pastejo. Revista Brasileira de Ciência do Solo, v.33, p.18291836, 2009. DOI: 10.1590/S0100-06832009000600031.

TEDESCO, M.J.; GIANELLO, C.; BISSANI, C.A.; BOHNEN, H.; VOLKWEISS, S.J. Análise de solo, plantas e outros materiais. 2.ed. rev. e ampl. Porto Alegre: Ed. da UFRGS, 1995. 174p. (UFRGS. Boletim técnico, 5).

VEZZANI, F.M.; MIELNICZUK, J. Agregação e estoque de carbono em Argissolo submetido a diferentes práticas de manejo agrícola. Revista Brasileira de Ciência do Solo, v.35, p.213-223, 2011. DOI: $10.1590 / \mathrm{S} 0100-06832011000100020$.

VIEIRA, F.C.B.; BAYER, C.; ZANATTA, J.A.; DIECKOW, J.; MIELNICZUK, J.; HE, Z.L. Carbon management index based on physical fractionation of soil organic matter in an Acrisol under long-term no-till cropping systems. Soil and Tillage Research, v.96, p.195-204, 2007. DOI: 10.1016/j.still.2007.06.007.

WEBER, O.L.S.; COUTO, E.G. Dinâmica da matéria orgânica no complexo do Pantanal. In: SANTOS, G. de A.; SILVA, L.S. da; CANELLAS, L.P.; CARMARGO, F. de O. (Ed.). Fundamentos da matéria orgânica do solo: ecossistemas tropicais \& subtropicais. 2.ed. rev. e atual. Porto Alegre, 2008. p. 463-482.

Recebido em 31 de agosto de 2015 e aprovado em 23 de fevereiro de 2016 